\title{
A NOVEL BANDPASS WAVEGUIDE FILTER STRUCTURE ON SIW TECHNOLOGY
}

\section{Z. Sotoodeh}

Iran University of Science and Technology

Iran

\section{B. Biglarbegian}

Ameritech Telecommunication research company Tehran, Iran

\section{F. H. Kashani}

Iran University of Science and Technology

Iran

\section{H. Ameri}

Ameritech Telecommunication research company Tehran, Iran

\begin{abstract}
Taking the advantage of common waveguide filters and SIW technology, a new filter structure is proposed. This structure can be implemented for various microwave frequencies by choosing appropriate low loss substrates. An example of suggested structure in $\mathrm{Ku}$ band is presented in this paper. The filter is designed and simulated on a low loss RT/Duroid 5880 laminate. The resulted filter has a Quality factor around 150. The main advantage of the structure is low size and cost, simplicity in fabrication, and the ability of integration with other elements of the circuit.
\end{abstract}

\section{INTRODUCTION}

The deployment of many millimeter-wave communication systems in the next decade, such as Local Multipoint Distribution Services (LMDS) or advanced collision avoidance sensor, requires a reduction of the production cost. Avoiding transitions between planar structures 
(such as microstrip circuits) and waveguide components is an effective way to reduce the cost and improve the performance of the product. On the other hand, these transitions are essential to integrate the microwave active and passive waveguide and planar components. Nevertheless, traditional technologies for passive components [22-24], including metallic rectangular waveguide or microstrip line [15-21], are too expensive or do not provide the required performance. Different solutions are proposed, that necessitates high precision mechanical process and possibility of fine tuning in mass production [1-3]. Recently, a new waveguide technology called the substrate integrated waveguide (SIW) has been proposed and developed as an attractive for low-cost, high-quality, relatively high-power, and high-density integration of microwave and millimeter-wave components and subsystems [4-8]. This waveguide is embedded in the same substrate used for the integration of the active part. In this way, all active and passive components can be integrated on a single substrate platform. In this paper, a metallic cylindrical inductive post waveguide filter is designed for realizing on SIW technology. In addition, a new transition of microstrip to SIW is proposed. The filter structure, including two transitions at the ports, is designed and simulated on RT/Duroid 5880 substrate in the $18 \mathrm{GHz}$ frequency band.

\section{MICROSTRIP TO SIW TRANSITION}

The SIW can be excited by a microstrip line connected to the middle of the SIW width, since the electric field of the dominant mode has the maximum intensity in the middle. Due to dispersion of the electrical field at the surface of the connection of the microstrip line and SIW for the forthright junction, one should consider other types of connection between these to transmission lines. Different configurations are suggested to improve the transition. Fig. 1(a) shows the configuration suggested in [9]. This configuration has applied to RT/Duroid 5880 substrate and the simulation result is shown in Fig. 2(b). The $S$ parameters depict a matched behavior of the transition for a bandwidth less than 5\%, as illustrated in Fig. 2(b).

A new configuration is suggested in this paper, to reach better results and increase the bandwidth. The structure is shown in Fig. 2(a) and its result is presented in Fig. 2(b). In this configuration, a smooth exponential change in microstrip line width is applied to connect to the SIW. A good improvement has been observed in $S$ parameters, compared to configuration suggested in [9] or direct connection.

The equation of this exponential curve is determined as follows:

$$
y=k e^{-\alpha x}-0.1
$$




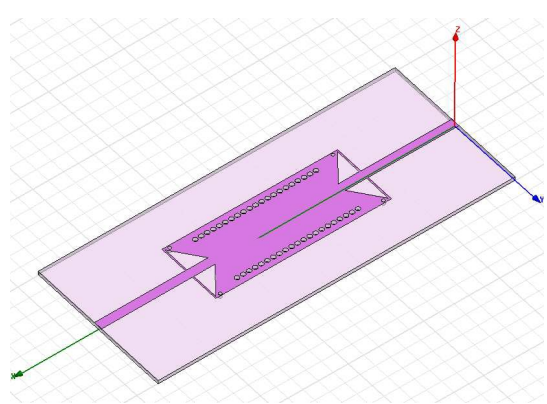

(a)

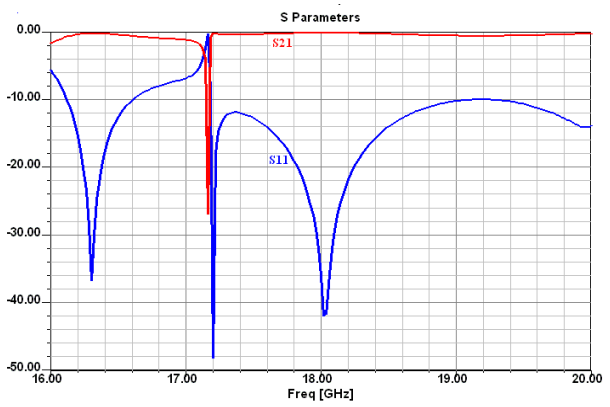

(b)

Figure 1. (a) The suggested transition in [9], (b) the simulated $S$ parameters of transition in [9].

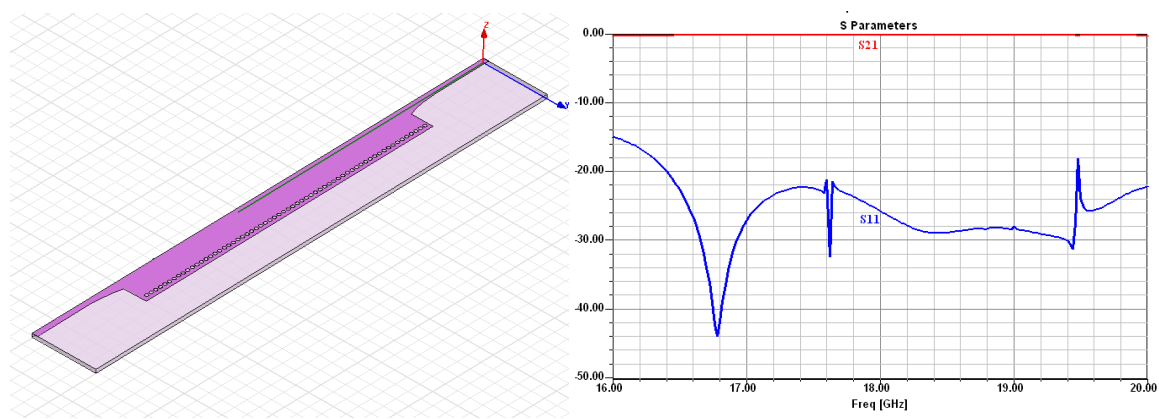

(a)

(b)

Figure 2. (a) The suggestion for the transition in this paper, (b) the simulated $S$ parameters of the new transition.

$$
\left\{\begin{aligned}
\alpha & =\frac{1}{x_{1}} \ln \left(\frac{0.1}{k}\right) \\
k & =\frac{\left(y_{1}-w\right)}{2}+0.1
\end{aligned}\right.
$$

where $x_{1}, y_{1}$, and the coordinate system are indicated in Fig. 3.

\section{FILTER DESIGN ON SIW TECH.}

There are several types of bandpass waveguide filters structures such as $E$-plane, $H$-plane, iris, and metallic cylindrical inductive post filters [11-13]. Nowadays, implementation of such filters on the SIW tech. is 


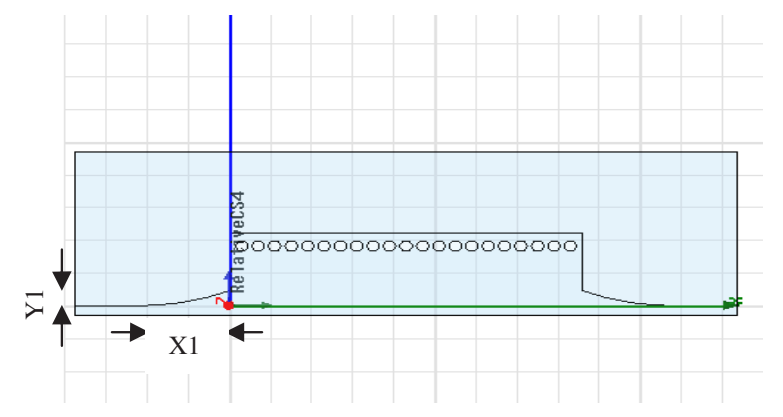

Figure 3. Top view of the structure and $X 1$ and $Y 1$ parameters.

a promising method for the next generation of the waveguide filters; since it can both reduce the fabrication size and costs effectively [14]. One of these filter structures that can be easily implemented on SIW, is the metallic cylindrical inductive post filter. The main advantage of this type is absolute realization of the posts by the cylindrical metallic vias on the substrate. Consider a couple of metallic cylinders located inside a rectangular waveguide. This structure and its equivalent circuit model are shown in Fig. 4. Such an equivalent circuit represents an impedance inverter and the aforementioned inverters were implemented in hollow waveguide before, massively.

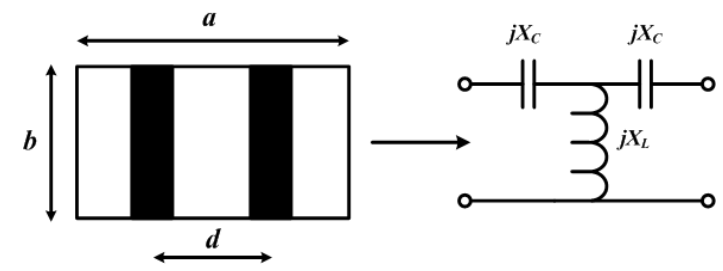

Figure 4. The cylindrical post and its equivalent circuit.

The inductive post filter at a waveguide filled by an arbitrary dielectric $\left(\varepsilon_{r}, \mu_{r}\right)$ can be designed by using this equivalent model, and considering impedance/admittance inverter concepts. The design procedure is explained completely in [10]. The procedure can be used for designing the SIW post filter, since all the equations are independent of $b$, the waveguide height.

An example of this filter has designed for RT/Duroid 5880 substrate with $\varepsilon_{r}=2.2$, and $h=20 \mathrm{mil}$. The centre frequency and bandwidth are $18.3 \mathrm{GHz}$ and $2 \%$ respectively. A schematic view of the designed filter is shown in Fig. 5. Note that $H$-plane symmetry is used to increase the simulation rate. 


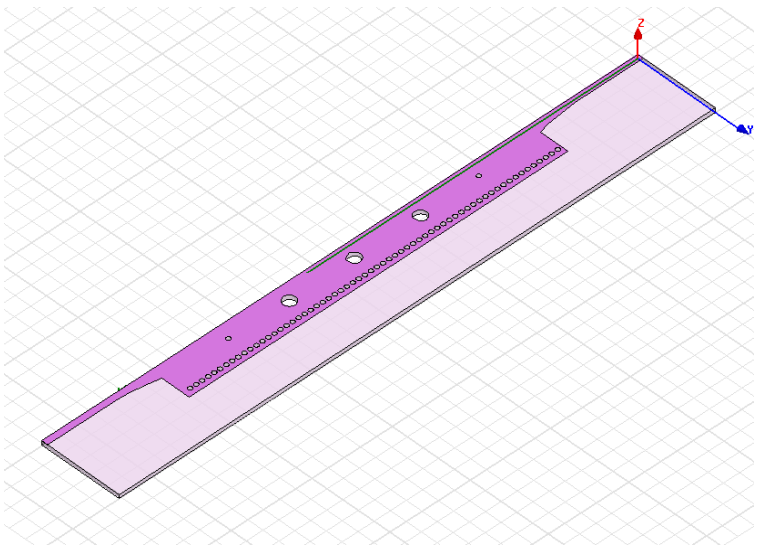

Figure 5. A schematic view of the designed filter.

\section{SIMULATION RESULTS}

The suggested microstrip to SIW adaptor in this paper has designed for the corresponding frequency and results are shown in Fig. 2. The resulted return loss is better than $20 \mathrm{~dB}$ at $16.5-20 \mathrm{GHz}$ band, and the insertion loss is less than $0.5 \mathrm{~dB}$, as illustrated in Fig. 2 .

The SIW post filter of order 4 has designed for centre frequency of $18.3 \mathrm{GHz}$ and $2 \%$ bandwidth. This design, including the adaptors at both ports, has simulated in HFSS and the results are depicted in Fig. 6 .
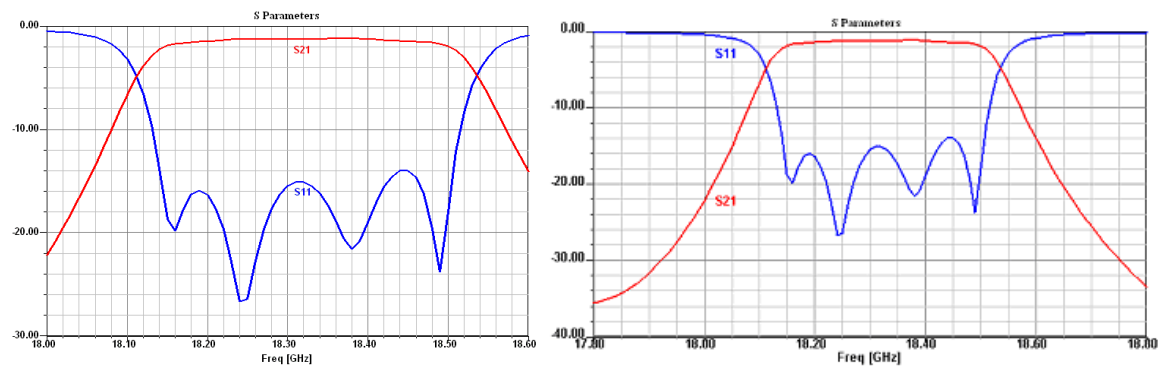

Figure 6. The $S$-parameters of the novel filter structure.

A good return loss is observed and the insertion loss is less than $2 \mathrm{~dB}$ in the pass band, using this configuration. 


\section{CONCLUSION}

Taking the advantages of substrate integrated waveguide; it is useful to implement common waveguide filter structures on this technology. In this paper an example of metallic inductive post waveguide filters on SIW technology has designed on RT/Duroid 5880 commercial substrate at $18.3 \mathrm{GHz}$ centre frequency. The filter has $50 \mathrm{~mm} \times 10 \mathrm{~mm}$ dimensions and the response has an insertion loss less than $2 \mathrm{~dB}$ in the band. The suggested filter can be scaled easily to the other frequency for low insertion and high $Q$ bandpass filters.

\section{REFERENCES}

1. Das, B. N., K. V. S. V. R. Prasad, and K. V. S. Rao, "Excitation of waveguide by stripline and microstrip-line-fed slots," IEEE Trans. Microwave Theory Tech., Vol. 34, 321-327, Mar. 1986.

2. Grabherr, W., B. Huder, and W. Menzel, "Microstrip to waveguide transition compatible with millimeter-wave integrated circuits," IEEE Trans. Microwave Theory Tech., Vol. 42, 18421843, Sept. 1994.

3. Ponchak, G. E. and R. N. Simons, "New rectangular waveguide to coplanar waveguide transition," IEEE MTT-S Int. Microwave Symp. Dig., Vol. 1, 491-492, May 1990.

4. Hirokawa, J. and M. Ando, "Single-layer feed waveguide consisting of posts for plane TEM wave excitation in parallel plates," IEEE Trans. Antennas Propagat., Vol. 46, 625-630, May 1998.

5. Deslandes, D. and K. Wu, "Integrated microstrip and rectangular waveguide in planar form," IEEE Microwave Wireless Comp. Lett., Vol. 11, 68-70, Feb. 2001.

6. Tzuang, C. K. C., K. C. Chen, C. J. Lee, C. C. Ho, and H. S. Wu, " $H$-plane mode conversion and application in printed microwave integrated circuit," Proc. Eur. Microwave Conf., Vol. 2, 37-40, Oct. 2000.

7. Jain, N. and N. Kinayman, "A novel microstrip mode to waveguide mode transformer and its applications," IEEE MTT-S Int. Microwave Symp. Dig., Vol. 2, 623-626, 2001.

8. Uchimura, H. and T. Takenoshita, "Development of a laminated waveguide," IEEE Trans. Microwave Theory Tech., Vol. 46, 24382443, Dec. 1998.

9. Nam, H., T. S. Yun, K. B. Kim, K. C. Yoon and J. C. Lee, "Ku-band transition between microstrip and substrate integrated waveguide (SIW)," IEEE APMC2005 Proceedings, 2005. 
10. Deslandes, D. and K. Wu, "Millimeter-wave substrate integrated waveguide filters," IEEE CCECE2003, 1917-1920, 2003.

11. Bahrami, H., M. Hakkak, and A. Pirhadi, "Analysis and design of highly compact bandpass waveguide filter using complementary split ring resonators (CSRR)," Progress In Electromagnetics Research, PIER 80, 107-122, 2008.

12. Khalaj-Amirhosseini, M., "Microwave filters using waveguides filled by multi-layer dielectric," Progress In Electromagnetics Research, PIER 66, 105-110, 2006.

13. Mohammad Amjadi, S. and M. Soleimani, "Design of bandpass waveguide filter using frequency selective surfaces loaded with surface mount capacitors based on split-field update FDTD method," Progress In Electromagnetics Research B, Vol. 3, 271$281,2008$.

14. Zhang, X.-C., Z.-Y. Yu, and J. Xu, "Novel band-pass substrate integrated waveguide (SIW) filter based on complementary split ring resonators (CSRRs)," Progress In Electromagnetics Research, PIER 72, 39-46, 2007.

15. Wu, G.-L., W. Mu, X.-W. Dai, and Y.-C. Jiao, "Design of novel dual-band bandpass filter with microstrip meanderloop resonator and CSRR DGS," Progress In Electromagnetics Research, PIER 78, 17-24, 2008.

16. Hasan, A. and A. E. Nadeem, "Novel microstrip hairpinline narrowband bandpass filter using via ground holes," Progress In Electromagnetics Research, PIER 78, 393-419, 2008.

17. Zhu, Y.-Z. and Y.-J. Xie, "Novel microstrip bandpass filters with transmission zeros," Progress In Electromagnetics Research, PIER 77, 29-41, 2007.

18. Prabhu, S., J. Mandeep, and S. Jovanovic, "Microstrip bandpass filter at S band using capacitive coupled resonator," Progress In Electromagnetics Research, PIER 76, 223-228, 2007.

19. Wang, Y.-X., B.-Z. Wang, and J. P. Wang, "A compact square loop dual-mode bandpass filter with wide stop-band," Progress In Electromagnetics Research, PIER 77, 67-73, 2007.

20. Chen, J., Z.-B. Weng, Y.-C. Jiao, and F.-S. Zhang, "Lowpass filter design of Hilbert curve ring defected ground structure," Progress In Electromagnetics Research, PIER 70, 269-280, 2007.

21. Zhao, L.-P., X. Zhai, B. Wu, T. Su, W. Xue, and C.-H. Liang, "Novel design of dual-mode bandpass filter using rectangle structure," Progress In Electromagnetics Research B, Vol. 3, 131$141,2008$. 
22. Li, G. and C.-H. Liang, "Design techniques for microwave diplexers," Progress In Electromagnetics Research B, Vol. 2, 103$113,2008$.

23. Eldek, A. A., "Wideband 180 degree phase shifter using microstrip-CPW-microstrip transition," Progress In Electromagnetics Research B, Vol. 2, 177-187, 2008.

24. Lee, Y., "CPW-to-stripline vertical via transitions for $60 \mathrm{GHz}$ LTCC SOP applications," Progress In Electromagnetics Research Letters, Vol. 2, 37-44, 2008. 